\title{
Effects of Subcutaneous Closed Suction Drain for the Prevention of Incisional SSI in Patients with Colorectal Perforation
}

\author{
Yasuo Sumi*, Kimihiro Yamashita, Kiyonori Kanemitsu, Shingo Kanaji, Masashi Yamamoto, \\ Tatsuya Imanishi, Tetsu Nakamura, Satoshi Suzuki, Kenichi Tanaka, Yoshihiro Kakeji \\ Division of Gastrointestinal Surgery, Department of SURGERY, Kobe University Graduate School of Medicine, \\ Kobe, Japan \\ Email: ${ }^{\text {ysumi0321@gmail.com }}$
}

Received 20 February 2014; revised 14 March 2014; accepted 21 March 2014

Copyright (C) 2014 by authors and Scientific Research Publishing Inc.

This work is licensed under the Creative Commons Attribution International License (CC BY). http://creativecommons.org/licenses/by/4.0/

CC) (i) Open Access

\begin{abstract}
Objective: To determine if a subcutaneous closed suction drain decreases the incidence of wound complications in patients undergoing emergency surgery for colorectal perforation. Materials and Methods: Data on 47 patients who underwent emergency operations for colorectal perforation were examined retrospectively. The clinical features of these cases with or without the use of the $\mathrm{J}^{\mathrm{VAC}}{ }^{\mathrm{TM}}$ Drainage System were examined, and statistical analysis was performed. Results: In these high-risk cases, the overall incidence of incisional surgical site infection (SSI) was $36.2 \%$. The incidence of incisional SSI in these cases with and without the $\mathrm{J}^{-\mathrm{VAC}^{\mathrm{TM}}}$ Drainage System was $16.7 \%$ and $56.5 \%$, respectively. Conclusion: Our results suggest that a subcutaneous closed suction drain is effective for preventing incisional SSI in patients who have undergone emergency operations for colorectal perforation.
\end{abstract}

\section{Keywords}

Surgical Wound Infection; Intestinal Perforation; Closed Suction Drainage; Emergency Operation

\section{Introduction}

Surgical site infection (SSI), including wound infection (incisonal SSI), is a frequent nosocomial infection. In colorectal surgery, its incidence was reported to be as high as 30\% [1] [2]. Incisional SSI leads to discomfort, delayed wound healing, and an increased risk of incisional hernia [3]. Previous studies of SSI were mainly of

\footnotetext{
${ }^{*}$ Corresponding author.
} 
those undergoing elective surgery and of risk factors for SSI [1] [4]-[8]. Most studies of the utility of a subcutaneous drain are based on gynecological operations, and information on the utility of subcutaneous drains in preventing incisional SSI remains controversial [9] [10].

Reports of digestive surgery failed to show the utility of a closed suction drain in preventing incisional SSI [11] [12]. Studies on prevention of incisional SSI in surgical wounds classified as III or IV based on the US Center for Disease Control and Prevention (CDC) classification are very few. Such wounds are at high risk for infection. Fujii et al. described the utility of a subcutaneous drain in providing effective drainage and reducing dead space in the subcutaneous wound area [13].

In this study we assessed the efficacy of the J-VAC TM Drainage System, which is a closed suction drain, for high-risk patients who underwent emergency operations for colorectal perforation.

\section{Materials and Methods}

\subsection{Patients}

Identified for inclusion in this retrospective study were 48 patients who underwent an emergency operation for perforation of the colon or rectum at the Kobe University Hospital from January 2008 to August 2013. Free air and fluid collection in the abdomen were confirmed by computed tomography. A patient who died on the 2nd postoperative day was excluded from the analysis, leaving a sample size of 47 cases. We compared the clinical features of these cases based on whether or not the J-VACTM Drainage System was used.

\subsection{Operative Procedures}

In all patients, the wound was irrigated with more than $500 \mathrm{ml}$ of $0.09 \%$ saline. A ring drape was used as a wound protector. The fascia/muscle layer was closed with 0 PDS ${ }^{\mathrm{TM}}$ (Ethicon, Inc., Somerville, NJ, USA).

In the 24 patients with the J-VAC ${ }^{\mathrm{TM}}$ Drainage System (Ethicon, Inc., Somerville, NJ, USA), a 10Fr. BLAKETM Silicon Drains (Ethicon, Inc.) was set subcutaneously and connected with the J-VAC ${ }^{\text {TM }}$ suction reservoir. The skin was closed with 4-0 PDS-II ${ }^{\mathrm{TM}}$ (Ethicon, Inc.). The exit of the drain was separated from the incision, and both the incision and drain exit were closed completely by sealing tape.

In the 23 patients without the drain, the skin was closed with a skin stapler and the incision was closed by absorbent tape. This tape was not changed for 2 days after the operation.

A regimen of systemic prophylactic antibiotics was strictly administered to all cases, with administration being started 30 minutes before incision, repeated every 3 hours during surgery, and stopped after the operation. If bacteria were confirmed by blood culture, systemic prophylactic antibiotics were administered intravenously following the operation.

We assessed the following specific variables that had a possible relationship to postoperative complications: age, gender, ASA grade, operation time, intraoperative blood loss, blood transfusion, ostomy formation, history of laparotomy, history of diabetes, preoperative steroid use, smoking habits, body mass index (BMI), thickness of subcutaneous fat (TSF), and pre-and post-operative serum albumin levels (Table 1).

\subsection{Statistical Analysis}

Statistical analysis was performed using JMP software (SAS Institute Inc., Cary, NC). The univariate relation between each independent variable and incisional SSI was compared using the Pearson $\chi^{2}$ test. Continuous normally distributed data were compared using Student's t-test. Significance was assumed when $\mathrm{p}<0.05$.

\section{Results}

Among the 47 cases, the overall incidence of incisional SSI was 36.2\%. There were no significant differences in factors such as age, gender, operation time, history of laparotomy, history of diabetes, smoking, BMI, TSF, and pre- and post-operative serum albumin levels between those with and without use of the J-VAC ${ }^{\text {TM }}$ Drainage System. The incidence of incisional SSI in the patients using the J-VAC ${ }^{\text {TM }}$ Drainage System was significantly lower than in those without drainage (16.7\% vs. 56.5\%) (Table 1). We defined that blood transfusion, ostomy formation, history of laparotomy, history of diabetes, preoperative steroid use, and smoking habits were the potential risk factors. Results of univariate analysis involving the use of the J-VAC ${ }^{\mathrm{TM}}$ Drainage System, when one or more of the potential risk factors was present, indicated that use of the J-VAC ${ }^{\text {тм }}$ Drainage System signifi- 
cantly reduced the incidence of SSI (Table 2).

\section{Discussion}

Perforation of the colon or rectum is categorized as Class IV (dirty-infected) based on the CDC definitions [14] and is considered to be an extremely high-risk condition. Several approaches to preventing SSI such as perioperative high inspired oxygen therapy, wound protectors, timing of antimicrobial prophylaxis, and subcutaneous drains have been reported [9]-[13] [15]-[17].

Some studies found that subcutaneous drains do not reduce the incidence of SSI [9]-[11]; however, subjects of these studies were not limited to high-risk patients. In the current study, the incisional SSI rate in patients with thick subcutaneous fat tissue was significantly reduced in high-risk cases, which is a result similar to that reported previously for obese women undergoing cesarean delivery [12] [13]. Furthermore, in the case of dirty wounds, the only study of the utility of a subcutaneous drain has been that by Fujii et al. [13].

This study assessed the efficacy of the J-VAC ${ }^{\mathrm{TM}}$ Drainage System as a subcutaneous closed suction drain

Table 1. Characteristics of patients with or without use of the J-VACтM drainage system.

\begin{tabular}{|c|c|c|c|c|}
\hline & & \multicolumn{2}{|c|}{ J-VAC drainage system } & \multirow[b]{2}{*}{$\mathrm{p}$ value } \\
\hline & & With $(n=24)$ & Without $(n=23)$ & \\
\hline Incisional SSI (n\%) & & $4(16.7 \%)$ & $13(56.5 \%)$ & 0.0043 \\
\hline Age (year old) & & $65(25-78)$ & $70(19-86)$ & n.s \\
\hline \multirow{2}{*}{ Gender } & Male & 12 & 16 & n.s \\
\hline & Female & 12 & 7 & \\
\hline \multirow{3}{*}{ ASA grade } & Grade 2 & 14 & 9 & n.s \\
\hline & Grade 3 & 7 & 10 & n.s \\
\hline & Grade 4 & 3 & 4 & n.s \\
\hline Operation time (min) & & $202(70-315)$ & $179(119$ - 424) & n.s \\
\hline Blood loss (ml) & & $400(5-2650)$ & $520(5-1950)$ & n.s \\
\hline Blood transfusion & & 12 & 13 & n.s \\
\hline Ostomy formation & & 21 & 4 & n.s \\
\hline History of laparotpmy & & 14 & 13 & n.s \\
\hline Diabetes & & 4 & 2 & n.s \\
\hline Preoperative steroid use & & 12 & 3 & 0.0339 \\
\hline Smoking & & 8 & 6 & n.s \\
\hline $\operatorname{BMI}\left(\mathrm{kg} / \mathrm{m}^{2}\right)$ & & $21.9(16.1-28.9)$ & $22.4(15.5-29.5)$ & n.s \\
\hline TSF (mm) & & $17.8(9-43)$ & $15(5-67)$ & n.s \\
\hline Preoperative albumin (g/dl) & & $2.55(1.4-3.9)$ & $2.6(0.6-4.2)$ & n.s \\
\hline Postoperative albumin (g/dl) & & $1.9(1.1-3.3)$ & $1.9(0.2-2.7)$ & n.s \\
\hline
\end{tabular}

SSI: surgical site infection; BMI: body mass index; TSF: thickness of subcutaneous fat, Median value (range).

Table 2. Incisional SSI after usage and non-usage of the J-VAC ${ }^{\mathrm{TM}}$ Drainage System in patients with one or more risk factors.

\begin{tabular}{cccc} 
& & \\
& J-VAC drainage system & \\
\hline & With $(\mathrm{n}=19)$ & Without $(\mathrm{n}=17)$ & $p$ value \\
Incisional SSI (n, \%) & $2(10.5 \%)$ & $9(52.9 \%)$ & 0.0058 \\
\hline
\end{tabular}

SSI: surgical site infection. 
system in patients undergoing surgery for colorectal perforation. Using the J-VAC ${ }^{\text {TM }}$ Drainage System was shown to be significantly more effective than not using such a system in preventing incisional SSI in high-risk patients undergoing emergency operations for colorectal perforation. Furthermore, in patients with factors such as history of laparotomy, history of diabetes, preoperative use of steroid, and a smoking habit, which were considered as risk factors of incisional SSI in previous reports [1] [4]-[7], the use of the J-VAC ${ }^{\mathrm{TM}}$ Drainage System was more effective.

Incisional SSI has some of the following causes: bacterial load, hematoma formation, subcutaneous effusion, subcutaneous dead space, and local ischemia of the skin or subcutaneous tissue. In addition to stitching the dermic layer and sufficient irrigation of the wound, the use of the J-VAC ${ }^{\text {TM }}$ Drainage System was effective in reducing the incidence of incisional SSI not only because of the continuous suction of the subcutaneous effusion, hematoma, and bacteria, but also because of reduction in the dead space of the subcutaneous wound area.

There are two types of subcutaneous drains: open drains, such as the Penrose drain, and closed suction drains, such as the J-VAC ${ }^{\mathrm{TM}}$ Drainage System. For drainage of subcutaneous effusion or blood, there is no difference between the Penrose drain and the J-VAC ${ }^{\text {тм }}$ Drainage System. However, in contrast to the Penrose drain, which is a passive drain using capillary action, the J-VACTM Drainage System is an active drain that employs by continuous suction. The J-VAC ${ }^{\mathrm{TM}}$ Drainage System has two characteristics: pressure is a maximum of $60 \mathrm{mmHg}$ so that the drainage is not excessive, and obstruction of the drainage tube is improbable because the BLAKE ${ }^{\mathrm{TM}}$ Silicon Drain is designed with 4 slits, so that if one slit is obstructed, suction can continue from the other openings (Figure 1). Thus, the J-VAC ${ }^{\text {тм }}$ Drainage System can reduce suction subcutaneous effusion and the dead space more effectively than a Penrose drain.

Another difference between the two drains is that the Penrose drain is an open drain and the J-VAC ${ }^{\text {TM }}$ Drainage System is a closed drain. From this viewpoint, the J-VACTM Drainage System can be considered to be more effective in preventing retrograde infection than a Penrose drain. As already noted, this was a retrospective study. In future, a prospective randomized trial of the utility of the J-VAC ${ }^{\mathrm{TM}}$ Drainage System in dirty wounds is necessary.

When J-VAC ${ }^{\mathrm{TM}}$ Drainage Systems are used, it is important to establish the starting point of suction at a precise position because the suction starts from an exact point in BLAKEтM Silicon Drains as shown in Figure 1.

Timing of removal of the drain tube varied widely among patients, as it depended on each surgeon. However, removal took place at a mean of the 7th postoperative day. Although the J-VAC ${ }^{\mathrm{TM}}$ Drainage System is a continuous suction drainage system, keeping it in place for more 7 days was reported to be likely to increase the risk of retrograde infection. Therefore, the timing of removal is very important. Early removal of a drain tube is ideal

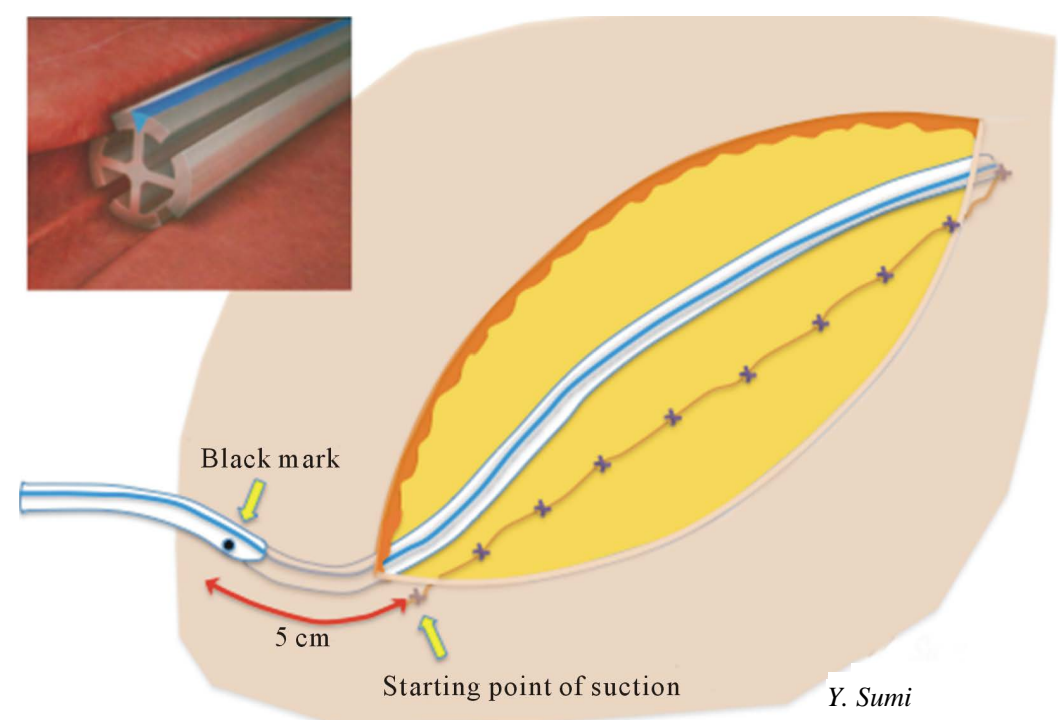

Figure 1. Shape of BLAKETM Silicone Drains and graphics of suction by the JVACTM Drainage System. BLAKEтM Silicone Drains is designed with 4 slits and can suction continuously from any one of the slits. Point of insertion of BLAKETM Silicone Drains. Starting point of suction is about $5 \mathrm{~cm}$ from black mark. 
in elective surgery, but the optimal removal time in patients with dirty wounds has not been studied. Additional research is needed on this point.

There was no significant difference in factors between those in whom the J-VACTM drainage system was and was not used, such as gender, operation time, pre- and post-operative serum albumin levels, BMI, TSF, and history of diabetes. Cases in which the J-VAC ${ }^{\mathrm{TM}}$ drainage system was utilized had significantly greater preoperative steroid use than those without use of the drainage system. This indicates that surgeons strongly felt that preoperative steroid use is a risk factor for incisional SSI.

This study has potential limitations. The number of cases was relatively small, and this was not a randomized study. Surgery for colorectal perforation is an emergency situation and is often performed in the middle of the night. Therefore, although a randomized trial on this topic would be very difficult, additional research is needed to explore this putative association.

\section{Conclusion}

In conclusion, we have demonstrated that a subcutaneous closed suction drain is effective in preventing incisional SSI in high-risk patients undergoing emergency operations for a colorectal perforation.

\section{Conflict of Interest}

The authors have no conflicts of interest.

\section{References}

[1] Konishi, T., Watanabe, T., Kishimoto, J. and Hirokazu, N. (2006) Elective Colon and Rectal Surgery Differ in Risk Factors for Wound Infection; Result of Prospective Surveillance. Annals of Surgery, 244, 758-763. http://dx.doi.org/10.1097/01.sla.0000219017.78611.49

[2] Bullard, K.M., Trudel, J.L., Baxter, N.N. and Rothenberger, D.A. (2005) Primary Perineal Wound Closure after Preoperative Radiotherapy and Abdominoperineal Resection Has a High Incidence of Wound Failure. Diseases of the Colon \& Rectum, 48, 438-443. http://dx.doi.org/10.1007/s10350-004-0827-1

[3] Murray, B.W., Cipher, D.J., Pham, T. and Anthony, T. (2011) The Impact of Surgical Site Infection on the Development of Incisional Hernia and Small Bowel Obstruction in Colorectal Surgery. The American Journal of Surgery, 202, 558-560. http://dx.doi.org/10.1016/j.amjsurg.2011.06.014

[4] Sehgal, R., Berg, A., Figueroa, R., Poritz, L.S., McKenna, K.J., Stewart, D.B. and Koltun, W.A. (2011) Risk Factors for Surgical Site Infections after Colorectal Resection in Diabetic Patients. Journal of the American College of Surgeons, 212, 29-34. http://dx.doi.org/10.1016/j.jamcollsurg.2010.09.011

[5] Malone, D.L., Genuit, T., Tracy, J.K., Gannon, C. and Napolitano, L.M. (2002) Surgical Site Infections: Reanalysis of Risk Factors. Journal of Surgical Research, 103, 89-95. http://dx.doi.org/10.1006/jsre.2001.6343

[6] Blumetti, J., Luu, M., Sarosi, G., Hartless, K., McFarlin, J., Parker, B., Dineen, S., Huerta, S., Asolati, M., Varela, E. and Anthony, T. (2007) Surgical Site Infections after Colorectal Surgery: Do Risk Factors Vary Depending on the Type of Infection Considered? Surgery, 142, 704-711. http://dx.doi.org/10.1016/j.surg.2007.05.012

[7] Sørensen, L.T., Hemmingsen, U., Kallehave, F., Jørgensen, P.W., Kjærgaard, J., Møller, L.N. and Jørgensen, T. (2005) Risk Factors for Tissue and Wound Complications in Gastrointestinal Surgery. Annals of Surgery, 241, 654-658. http://dx.doi.org/10.1097/01.sla.0000157131.84130.12

[8] Watanabe, A., Kohnoe, S., Shimabukuro, R., Yamanaka, T., Iso, Y., Baba, H., Higashi, H., Orita, H., Emi, Y., Takahashi, I., Korenaga, D. and Maehara, Y. (2008) Risk Factors Associated with Surgical Site Infection in Upper and Lower Gastrointestinal Surgery. Surgery Today, 38, 404-412. http://dx.doi.org/10.1007/s00595-007-3637-y

[9] Hellums, E.K., Lin, M.G. and Ramsey, P.S. (2007) Prophylactic Subcutaneous Drainage for Prevention of Wound Complications after cesarean delivery. A Metaanalysis. American Journal of Obstetrics \& Gynecology, 197, $229-235$. http://dx.doi.org/10.1016/j.ajog.2007.05.023

[10] Kumar, S.A. (2004) Subcutaneous Drain versus Subcutaneous Stitch Closure to Prevent Wound Disruption after Cesarean Section. Journal of Obstetrics \& Gynaecology of India, 54, 237-242.

[11] Baier, P.K., Gluck, N.C., Baumgartner, U., Adam, U., Fischer, A. and Hopt, U.T. (2010) Subcutaneous Redon Drains Do Not Reduce the Incidence of Surgical Site Infections after Laparotomy. A Randomized Controlled Trial on 200 Patients. International Journal of Colorectal Disease, 25, 639-643. http://dx.doi.org/10.1007/s00384-010-0884-y

[12] Chowdri, N.A., Qadri, S.A., Parray, F.Q. and Gagloo, M.A. (2007) Role of Subcutaneous Drains in Obese Patients Undergoing Elective Cholecystectomy: A Cohort Study. International Journal of Surgery, 5, 404-407. 
http://dx.doi.org/10.1016/j.ijsu.2007.05.011

[13] Fujii, T., Tabe, Y., Yajima, R., Yamaguchi, S., Tsutsumi, S., Asao, T. and Kuwano, H. (2011) Effects of Subcutaneous Drain for the Prevention of Incisional SSI in High-Risk Patients Undergoing Colorectal Surgery. International Journal of Colorectal Disease, 26, 1151-1155. http://dx.doi.org/10.1007/s00384-011-1228-2

[14] Mangram, A.J., Horan, T.C., Pearson, M.L., Silver, L.C. and Jarvis, W.R. (1999) Guideline for Prevention of Surgical Site Infection. Infection Control and Hospital Epidemiology, 20, 247-278.

[15] Smith, R.L., Bohl, J.K., McElearney, S.T., Friel, C.M., Barclay, M.M., Sawyer, R.G. and Foley, E.F. (2004) Wound Infection after Elective Colorectal Resection. Annals of Surgery, 239, 599-607. http://dx.doi.org/10.1097/01.sla.0000124292.21605.99

[16] Murray, B.W., Huerta, S., Dineen, S. and Anthony, T. (2010) Surgical Site Infection in Colorectal Surgery: A Review of the Nonpharmacologic Tools of Prevention. Journal of the American College of Surgeons, 211, 812-822. http://dx.doi.org/10.1016/j.jamcollsurg.2010.07.025

[17] Hagihara, M., Suwa, M., Ito, Y., Muramatsu, Y., Kato, Y., Yamagishi, Y. and Mikamo, H. (2012) Preventing SurgicalSite Infections after Colorectal Surgery. Journal of Infection and Chemotherapy, 18, 83-89. http://dx.doi.org/10.1007/s10156-011-0298-y 